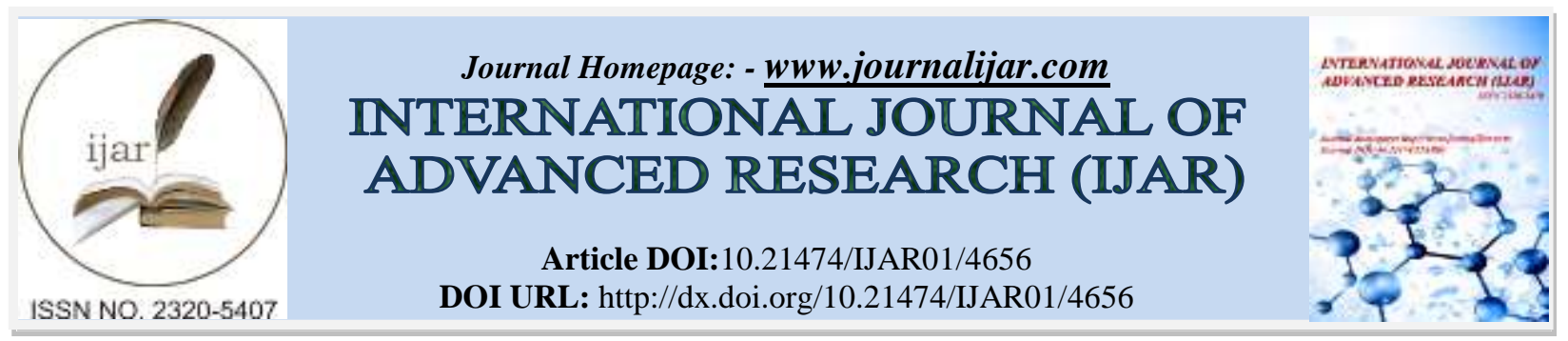

RESEARCH ARTICLE

\title{
COMPARATIVE EVALUATION OF ULTRASONOGRAPHY AND COMPUTED TOMOGRAPHY FINDINGS IN RENAL MASSES.
}

\author{
Dr. Jaswinder Kaur Mohi, Dr. Sunita and Dr. Manoj Mittal. \\ Radiology gmc Patiala.
}

\section{Manuscript Info}

\section{Manuscript History}

Received: 20 April 2017

Final Accepted: 25 May 2017

Published: June 2017

\section{Abstract}

Introduction: Renal masses include a heterogenous group of kidney lesions which lead to enlargement of kidney. Both benign and cancerous growths can cause increase in kidney size. The advent of USG and CT in recent years has lead to the early recognition of small asymptomatic lesions during the examination performed for the reasons other than for a suspected renal mass. It is recommended that USG should be the initial screening modality in a patient suspected of having renal mass and CT should be used for further characterisation of the lesion as well as the staging of the malignant lesion. In the present study we evaluated the diagnostic accuracy of ultrasound and $\mathrm{CT}$ in the detection of renal masses and comparison of findings of these imaging modalities.

\section{Aims and objective:}

1. To evaluate the patients with renal masses by ultrasonography [USG] and computed tomography[CT].

2. Comparision of findings of USG and CT.

Material and methods:

The prospective study was carried out in the Department of Radiodiagnosis, Rajindra Hospital, Patiala.The present study included 60 patients.Patients presenting with clinically suspected renal masses confirmed on USG in both males and females of any age group were included in the present study.

Results:Out of 60 patients included in study RCC was found in 29 patients, Wilm'stumour in 3, metastasis in 4, renal lymphoma in 2 , angiomyolipoma in 4 , abscess in 7 , pyonephritis in 4 , hydatid cyst in 1 , renal hematoma in 1 , perinephric collection in 1 , oncocytoma in 1 , complex cyst in 2 patients and adrenal mass in 1 patient.In evaluation of renal masses on $\mathrm{CT}$,our study shows 96.55\% sensitivity,96.77\% specificity, $96.55 \%$ positive predictive value, $96.77 \%$ negative predictive value and $96.6 \%$ accuracy. In .In evaluation of renal masses on USG,our study shows $89.66 \%$ sensitivity, $87.10 \%$ specificity, $86.66 \%$ positive predictive value, $90.0 \%$ negative predictive value and $88.3 \%$ accuracy. 


\section{Introduction:-}

The renal masses comprise a large variety of space occupying lesions, which are composed of nonfunctioning renal tissue. Most of them are neoplastic, while some of these are inflammatory, congenital, cystic or traumatized tissue. Renal neoplasm can be either benign or malignant. Renal cell carcinoma is the most common primary malignancy of kidneyaccounting for $2 \%$ of all cancer diagnoses ${ }^{[1]}$ and Wilm's tumour being the most common childhood tumour. ${ }^{[2]}$ Other important neoplasms are angiomyolipoma, oncocytoma, multilocular cystic nephroma, hemangioma, lymphoma, sarcoma, metastases, transitional cell carcinoma and squamous cell carcinoma.

Usual clinical presentation of malignant renal neoplasm is in the form of hematuria, flank pain or lump abdomen. However, benign lesions including benign cortical cysts remain asymptomatic most of times and are discovered incidentally on USG or CT.Renal neoplasms were usually detected late in their course in the past when the lesions had already metastasized. Surgical exploration was done in the less aggressive lesions to establish histopathological confirmation but the reliance on surgical exploration and histological diagnosis was challenged increasingly. Simultaneously various studies claimed that sequential use of radiological investigations can identify the nature of renal masses with diagnostic accuracy comparable to that of surgical exploration.

There is tremendous advancement in the visualization of urinary tract disorders in the past two decades especially in the detection and characterization of renal masses and even early recognition of small asymptomatic lesions with a high detection rate can be achieved by the sequential use of various recent diagnostic modalities that includes plain radiography, excretory urography, ultrasonography, computed tomography (CT) and magnetic resonance imaging(MRI).

Plain abdominal radiograph (KUB) may rarely be used now as the first study to alert the radiologist to the presence of a renal mass, similarly intravenous urography (IVU) may sometimes be the initial study to depict a renal mass.

Ultrasonography (USG) is often the initial modality for imaging of the kidneys, although contrast enhanced CT is an established imaging modality for the diagnosis of renal tumors. ${ }^{[3]}$ Ultrasound has a primary role in differentiating cystic from solid lesions and is superior to CT in demonstrating the complex internal architecture of cystic lesions in terms of internal fluid content, septations, tiny nodules and wall abnormalities including associated soft tissue masses. ${ }^{[4]}$ Ultrasonography is easily performed without the need for sedation or ionizing radiation and without requirement of intravenous contrast injection so it is valuable for children, pregnant women and those having impaired renal function or sensitivity to iodinated contrast media. It is portable, relatively inexpensive and readily available in small towns and is thereby the best and most common screening procedure for detection of renal lesions especially in our country where $40 \%$ population is below poverty line. Recently, pulsed doppler USG and colour doppler flow imaging (CDFI) has shown promise in not only differentiating between different types of renal masses by intralesional blood flow patterns but also the extension of the tumour intralesionally.

The primary limitation of USG include problems related to incomplete staging(bones,lungs, regional nodes) and to the detection of small non contour deforming masses

CT has a profound impact on diagnostic uroradiology among all modern modalitiesdespite the availability of less expensive imaging methods particularly USG and MRI. CT has continued to play a major role in the diagnosis and follow-up of patients with urologic disease. Its non-invasive nature and extremely high diagnostic yield ultimately makes it an integral component of uroradiological diagnosis. ${ }^{[5]}$ It is more accurate in delineating a renal mass and in differentiating between a pseudomass and a normal anatomic variant from a tumour and allows studies in patients who have dense renal calcification or in whom USG is technically difficult. It should be used in many areas for definite evaluation of lesions suspected from other studies, for example IVU or USG. But for many disorders, like angiomyolipoma, calcified renal mass or para-pelvic cyst etc. the diagnostic power of CT is so definitive that its use as the primary diagnostic procedure is justified and other studies are not required. Dynamic thin section CT is highly accurate in evaluating tumour extension into the renal vein or IVC but MRI or USG may be helpful in identifying the cephalic extent of the tumour.CT is the method of choice for post nephrectomy renal fossa surveillance following the treatment.

Primary limitation of CT is the characterization of hypoattenuation in masses smaller than 8-10mm,in which pseudoenhancement may be a problem.US may be of some use in characterization the lesions as cysts. 
The aim of the study was to elucidate the role of helical CT and USG in the evaluation of renal masses and correlation of USG and CT findings.

\section{Material And Methods:-}

The prospective study was carried out in the Department of Radio-diagnosis, Rajindra Hospital, Patiala.The present study included 60 patients.

Patients presenting with clinically suspected renal masses confirmed on USG in both males and females of any age group were included in the present study. Patients presenting with simple cysts on USG were not included in the present study. Relevant history, clinical examination and routine investigations were done.Patients underwent ultrasonography (USG) and computed tomograpghy (CT scan) investigations. FNAC was done when required.

Requirements for the present study:

Ultrasound machine (Philips Envisor)

CT Scanner (Siemens Somatom Emotion 6-slice)

\section{Ultrasonography:-}

\section{Technique:-}

USG was performed with Philips Envisor machine. An appropriate transducerfrequency ranging from 2.5 to $5 \mathrm{MHz}$ was used, depending on the body habitus. The sonographic examination of the kidneys included long axis and transverse views of the upper poles, midportions, and the lower poles, with assessment of the cortex and central sinus. Kidneys and perirenal regions were assessed for abnormalities.

\section{CECT Scan:-}

\section{Technique:-}

Examination were conducted on Siemens Somatom Emotion, six slice CT machine. Slice thickness of $8 \mathrm{~mm} \times \mathrm{mm}$ collimation was used. Precontraststudy of the kidneys was performed initially followed by the postcontrast study of the kidneys, 70-80 seconds after the initiation of intravenous bolus of contrast injection. Initial post contrast study was performed in the nephrographic phase of renal enhancement. Delayed CT was performed using same parameters as used in initial postcontrast study.

\section{Contrast Material:-}

Nonionic iodine contrast $300 \mathrm{mg}$ was used in our study. $100 \mathrm{ml}$ of contrast was injected intravenously by the peripheral intravenous route at the rate of $2-3 \mathrm{ml} / \mathrm{sec}$. Continuous monitoring of the vital parameters was done during contrast injection.

\section{Observations:-}

This prospective study was carried out in Rajindra Hospital, Patiala. Sixty patients were selected from the OPD and wards of the hospital. Relevant data about patient's name, age, sex, clinical history, physical examination and routine relevant investigations were recorded as per plan. Various parameters as described in material and methods were studied and from these parameters, observations were recorded.Following tables, charts and illustrations were made to achieve the aims and objectives of our study.

Table1:- Distribution of total patients included in study according to type of renal mass found.

\begin{tabular}{|c|c|}
\hline Type of Lesion & No. of Cases \\
\hline Renal cell carcinoma & $29(48.3 \%)$ \\
\hline Wilm'stumour & $03(5 \%)$ \\
\hline Metastasis & $04(6.66 \%)$ \\
\hline Renal lymphoma & $02(3.33 \%)$ \\
\hline Oncocytoma & $01(1.66 \%)$ \\
\hline Angiomyolipoma & $04(6.66 \%)$ \\
\hline Renal abscess & $07(11.66 \%)$ \\
\hline Pyelonephritis & $04(6.66 \%)$ \\
\hline Hydatid cyst & $01(1.66 \%)$ \\
\hline Renal hematoma & $01(1.66 \%)$ \\
\hline Perinehric collection & $01(1.66 \%)$ \\
\hline Complex cyst & $02(3.33 \%)$ \\
\hline
\end{tabular}


In 60 patients renal masses were found in 59 patients. In one patient one lesion diagnosed as RCC on USG and CT, that was actually adrenal mass on biopsy.

Out of 60 patients included in study RCC was found in 29 patients, Wilm'stumour in 3, metastasis in 4, renal lymphoma in 2,angiomyolipoma in 4, abscess in 7, pyonephritis in 4, hydatid cyst in 1, renal hematoma in 1 , perinephric collection in 1, oncocytoma in 1, complex cyst in 2 patients and adrenal mass in 1 patient.

USG correctly diagnosed 26 cases of RCC while CT detected 28 cases (true positive). USG report was normal in one case but it was RCC on CT. In second case in which USG report revealed renal abscess, it was found to be RCC on CT which was later confirmed on FNAC. One case was diagnosed as renal abscess on both USG and CT that was found to be RCC on biopsy (false negative). USG findings were suggestive of renal mass in two patients but when CT was done no solid component was seen and these cases were diagnosed as complex cysts (false positive). One lesion appears hypoechoic on USG and, CT was advised to rule out any focal mass.It was found to be a focal perinephric collection on CT scan (false positive). One patient was diagnosed to have RCC on both USG and CT but biopsy revealed adrenal mass (false positive). Out of these 29 cases 23 patients get FNAC done which confirmed USG and CT findings.

Table 2:- Appearanceof rcc onusg and ct.

\begin{tabular}{|c|c|c|c|c|}
\hline & No of lesions detected & Solid & Cystic & Solid/cystic \\
\hline USG & 26 & 22 & 2 & 2 \\
\hline CT & 28 & 24 & 1 & 3 \\
\hline
\end{tabular}

Out of 26 lesions detected by USG, $22(84 \%)$ masses were solid and 2 masses were cystic and on the other hand out of 28 cases, $24(85 \%)$ masses were solid and 1 wascystic on appearance in CT. Cystic mass was found on USG in one patient but when CT was performed it shows enhancing nodule that was later found to be cystic RCC on FNAC.2 lesions show solid and cystic component on both USG and CT.

Table no 3:-Echopattern on usg

\begin{tabular}{|c|c|c|c|}
\hline ISOECHOIC & HYPOECHOIC & HYPERECHOIC & HETEROGENOUS \\
\hline $15(57.6 \%)$ & $02(7.6 \%)$ & $02(7.6 \%)$ & $07(26.9 \%)$ \\
\hline
\end{tabular}

Table no4:- Appearance on ct

\begin{tabular}{|c|c|}
\hline HETEROGENOUS & CYSTIC \\
\hline $27(96.4 \%)$ & $01(3.5 \%)$ \\
\hline
\end{tabular}

Most common echopattern on ultrasound was isoechoic in $57.6 \%$ followed by heterogenous and hypoechoic. $96 \%$ masses were heterogenous followed by cystic lesions on CT $(3.5 \%)$.

Table no 5:- Bosnaik classification of cystic lesions

\begin{tabular}{|c|c|c|}
\hline & CYSTIC LESION & SOLID AND CYSTIC LESION \\
\hline USG & 2 & 2 \\
\hline CT & 1(Bosnaik type 2) & 3(Bosnaik type 3/4) \\
\hline
\end{tabular}

Two lesions were detected as cystic masses on USG, one of these shows internal echoes on USG and was found to be cystic mass with enhancing septae on CT (Bosnaik type 2). Enhancing nodules were seen on CT in second cystic lesion (Bosnaik type 3/4) detected by USG.Other two lesions showed both solid and cystic components on both USG and CT (Bosnaik type 3/4).

Table no6:- Imaging chracterstics of rcc found on usg and ct

\begin{tabular}{|c|c|c|}
\hline IMAGING FEATURES & ULTRASOUND & CT \\
\hline Calcification & 06 & 13 \\
\hline Collaterals & 00 & 06 \\
\hline Fat component & 00 & 01 \\
\hline Perinephric extension & 00 & 15 \\
\hline IVC Thrombus & 02 & 02 \\
\hline Lymphadenopathy & 02 & 02 \\
\hline
\end{tabular}


Calcification was seen in 13 cases on CT and in 6 cases on USG. LAP was seen in 17 cases on CT and in 11 cases on USG. IVC thrombus was seen in 2 cases on USG and CT. CT additionally detected perinephric extension in 15 cases, collaterals in 6 cases and fat component in one lesion.

Table 7:- Imaging features of wilm's tumour on ct and usg

\begin{tabular}{|c|c|c|}
\hline IMAGING FEATURES & USG & CT \\
\hline Appearance & Heterogenous-3 & 2 \\
\hline Necrotic areas & 0 & 1 \\
\hline Perinephric extension & 0 & 3 \\
\hline Lymphadenopathy & 2 & 0 \\
\hline IVC invasion & 0 & Hetens-3 \\
\hline
\end{tabular}

Echopattern was heterogenous and predominantly hyperechoic in one lesion and heterogenous in other two lesions on USG. Appearance was heterogenous in three cases on CT.Perinephric extension was seen in one case and necrotic areas in two cases on CT.LAP was seen in all of 3 cases on CT and in 2 cases on USG. No invasion of IVCwas seen in any of three cases on both modalities.

\section{Angiomyolipoma:-}

Out of 60 cases angiomyolipoma was found in 4 cases.

Both USG and CT correctly detected two of these cases as angiomyolipoma. In one case, which appears mildly hyperehoic on USG, possibility of RCC was given but on CT this lesion shows minimal amount of fat and was diagnosed as angiomyolipoma that was later confirmed on pathological correlation. One case was diagnosed as hematoma on USG but when CT was done this lesion contains fat and was found to be angiomyolipoma associated with hemorrhage.

\section{Oncocytoma:-}

Out of 60 patients, one patient was found to have a well-defined homogenous mass on USG, which on CT showed central scar suggestive of oncocytoma.This case was confirmed as renal oncocytoma on biopsy.

\section{Metastatic lesions:-}

Out of 60 cases, metastatic lesions were found in four cases.

In one pt with no known primary malignancy,multiple lesions were seen in b/l kidneys associated with abdominal lap on USG. When CT was done multiple b/l renal lesions with abdominal lap was found. A well-defined hypodense lesion was also found in liver and a heterogenous mass with spiculated margins was found in available sections of lung in right lower lobe. When biopsy was done it was diagnosed as case of bronchogenic carcinomawith renal and hepatic metastasis.

Out of two patients of ca oesophagus, USG detected heterogenous mass in one patient, when CT was done heterogenous mass with perinephric extension and abdominal lap was found. In other patient with normal ultrasound, CT detected a heterogenous mass of $2.8 \mathrm{~cm}$ in right kidney.

In fourth patient (known case of ca sigmoid colon) USG detected one renal lesion and CT detected multiple renal lesions (3 in number). Abdominal lap was found on both USG and CT. Multiple hepatic lesions were also seen on both USG and CT. CT also detected lytic lesions in vertebral bodies.

Table 8:- Imaging fetures of metastatic lesions on usg and ct

\begin{tabular}{|c|c|c|}
\hline & USG & CT \\
\hline Detected Lesions & 4 & 7 \\
\hline Lymphadenopathy & 2 & 3 \\
\hline Perinephric extension & 0 & 1 \\
\hline
\end{tabular}

\section{Renal lymphoma:-}

Multiple bilateral renal hypodense masses associated with retroperitoneal lymphadenopathy were found on USG in one patient. CT detected multiple poorly enhancing homogenous bilateral renal masses associated with 
retroperitoneal lymphadenopathy (LAP). One renal lesion shows exophytic component on CT. Some of nodal masses cause impression on kidneys and there was also seen encasement of renal vessels by lymph nodes on computed tomography. In second patient bilateral renal masses were seen on both modalities. Masses were seen displacing the pelvi-calyceal system medially.Insignificant lymph nodes in mesentery and retroperitonium were also found on CT. These cases were diagnosed as lymphoma with renal involvement by pathological correlation.

\section{Renal Abscess:-}

Out of 60 cases renal abscesses were found in 7 patients

Table 9:- imaging features of renal abscesses on ct and usg

\begin{tabular}{|c|c|c|}
\hline & USG & CT \\
\hline Lesions detected & 7 & 8 \\
\hline Appearance & $\begin{array}{c}\text { Hypoechoic-5 } \\
\text { Heterogenous-2 }\end{array}$ & $\begin{array}{c}\text { Hypodense-5 } \\
\text { Heterogenous-3 }\end{array}$ \\
\hline Rim enhancement & & 6HT-Enhancement-2 \\
\hline Wall of lesion & $\begin{array}{c}\text { Well defined walls-5 } \\
\text { Illdefined walls-2 }\end{array}$ & $\begin{array}{l}\text { Thick and irregular-6 } \\
\text { Well defined walls-2 }\end{array}$ \\
\hline Intralesional air & 1 & 1 \\
\hline Perinephric extension & 2 & 6 \\
\hline Perinephric fluid & 0 & 1 \\
\hline Lymphadenopathy & 3 & 5 \\
\hline $\begin{array}{c}\text { Psoas muscle Thickening } \\
\text { Psoas abscess }\end{array}$ & $\begin{array}{l}3 \\
0\end{array}$ & $\begin{array}{l}2 \\
2\end{array}$ \\
\hline
\end{tabular}

In these 7 patients, both modalities detected 7 lesions. In one patient USG detected only one lesion while CT revealed two lesions, second lesion that was missed on USG was smaller in size $(2.4 \mathrm{~cm})$. On USG, 5 lesions were hypoechoic andtwo were heterogenous in echopattern on USG. On CT, 5 lesions were hypodense and three were heterogenous. CT showed rim enhancement in 6 lesions, heterogenous enhancement in 2 lesions, perinephric fluid in 1 case,perinephric extension in 6, LAP in 5, psoas abscess in 2, psoas thickening in 2 and intralesional air in one case. USG detected perinephric extension in 2, LAP in 3 and psoas thickening in 3 cases. Psoas abscess was not separately identified on USG from renal abscess.

\section{Pyelonephritis:-}

Out of 60 cases pyelonephritis was found in 4 cases.

Table 10:- Imaging features of pyelonephritis on ct and usg.

\begin{tabular}{|c|cc|}
\hline & USG & CT \\
\hline Appearance & HT-4 & HT-4 \\
\hline Perinephric extension & 0 & 3 \\
\hline Perinephric fat stranding & 0 & 1 \\
\hline Thickening of psoas muscle & 0 & 1 \\
\hline Lymphadenopathy & 1 & 1 \\
\hline Intralesional fat & 0 & 1 \\
\hline Calculus & 1 & \\
\hline
\end{tabular}

Out of 4 cases, 3 cases were detected, as pyelonephritis on USGthat was later confirmed on CT. Appearance was heterogenous in 3 lesions on both modalities. Perinephric extension was seen on CT in two cases, and perinephric fat stranding in one case. CT showed mild thickening of psoas muscle in one case. LAP was seen in one case on USG and in two cases on CT. Both modalities showed a heterogenous mass with calculus in one patient. Perinephric extension and fatty component was also seen on CT and it was diagnosed as a case of xanthogranulomatous pyelonephritis, which was later on confirmed pathologically. 
Table 11:- Imaging features of renal hydatid cyst on usg and ct

\begin{tabular}{|c|c|c|}
\hline & USG & CT \\
\hline Appearance & Hypoechoic & Hypodense non enhancing \\
\hline Calcification & + & + \\
\hline Perinephric extension & - & + \\
\hline
\end{tabular}

One patient out of 60 patients presented with swelling of right lumbar region after trauma, which was correctly detected as hematoma on both modalities. USG shows a large hypodense lesion involving almost whole of renal parenchyma that was extending superiorly to inferior surface of liver. When CT was done lesion appears nonenhancing hyper attenuating (50-60 HU)involving upper and middle poles of right kidney. Lower pole shows normal excretion of contrast. Lesion was seen extending superiorly and indenting inferior surface of liver, medially lesion was seen extending to right paraaortic region and causing narrowing of IVC. The lesion displaced renal vessels anteriorly. CT also demonstrates extravasation of contrast material in hematoma.

Two lesions appeared cystic on USG with internal septations without any solid component, which were correctly diagnosed as complex renal cysts on CT.

One lesion appeared hypoechoic on USG and CT was advised to rule out any focal mass. It was found to be a focal perinephric collection on CT scan.

One case out of 60 diagnosed as upper pole RCC on both modalities, which was found to be adrenal lesion on biopsy.

\section{Discussion:-}

Out of 60 patients included in our study, RCC was most commonly found renal lesions constitute 29(48.33\%) of total renal lesions followed by angiomyolipoma/metastasis $4(6.66 \%)$ and Wilm'stumour $3(5 \%)$ as shown in Table 3. Neoplastic lesions constitute $71.6 \%$ and inflammatory lesions constitute $23.3 \%$ of total lesions.

Our study correlates with study of Bajwa et $\mathrm{al}^{[48]}$ in which renal cell carcinoma was the commonest found renal lesion (45.8\%) followed by Wilm'stumour (4.28\%), transitional cell carcinoma (2.8\%), lymphoma and angiomyolipoma (AML) in 1.4\% each. Neoplastic lesions were observed in 39 (55.7\%) cases and inflammatory lesions in 23 cases $(32.9 \%)$ in there study.

RCC was also commonly detected and evaluated renal neoplasm in study of Hatimota et al ${ }^{[46]}$.

In studies conducted by Linblad ${ }^{[50]}$, Lipworth et $\mathrm{al}^{[51]}$ and $\mathrm{NG}$ et $\mathrm{al}^{[52]}$ renal cell carcinoma emerged as the commonest tumour in men than in women.

Table 8:- Rcc detection on usg.

\begin{tabular}{|c|c|}
\hline True Positive & 26 \\
\hline True Negative & 27 \\
\hline False Positive & 04 \\
\hline False Negative & 03 \\
\hline Sensitivity (\%) & 89.66 \\
\hline Specificity (\%) & 87.10 \\
\hline Positive Predictive Value (\%) & 86.67 \\
\hline Negative Predictive Value (\%) & 90.00 \\
\hline Accuracy (\%) & 88.3 \\
\hline
\end{tabular}

Table 9:- Rcc detection on ct

\begin{tabular}{|c|c|}
\hline True Positive & 28 \\
\hline True Negative & 30 \\
\hline False Positive & 01 \\
\hline False Negative & 01 \\
\hline Sensitivity (\%) & 96.55 \\
\hline Specificity (\%) & 96.77 \\
\hline Positive Predictive Value (\%) & 96.55 \\
\hline Negative Predictive Value (\%) & 96.77 \\
\hline Accuracy (\%) & 96.6 \\
\hline
\end{tabular}


In study conducted by Warshauer et $\mathrm{al}^{[25]}$ specificity, positive predictive value and negative predictive value of USG for the detection of renal masses were $91 \%, 82 \%$ and $73 \%$ respectively. Our study correlates with study of Levitt et $\mathrm{al}^{[11]}$ which concluded that CT and USG offer complementary and supplementary role in the evaluation of renal and pancreatic disease.In their study specificity, sensitivity, positive predictive value and negative predictive value of CT for detection of renal masses were $100 \%, 90 \%, 100 \%$ and $96.88 \%$. Accuracy was $97 \%$ as against $96.6 \%$ in our study. However, sensitivity of USG was $60 \%$ in their study that is low in comparison to our study (89.66\%). Specificity, positive predictive value, negative predictive value and accuracy were 100\%, 100\%, 84\% and $87 \%$ respectively.

Our study correlates with studies of Sagel et al ${ }^{[5]}$ (1977), Bajwaet al ${ }^{[48]}$ (2007), King ${ }^{[9]}$ (1972) and Dachille et $\mathrm{al}^{[53]}(2005)$ that demonstrated similar values as in present study for the detection of renal masses on USG and CT as shown Table 22 and Table 23.

Table 10:- Role of ct in evaluation of renal masses in different studies

\begin{tabular}{|c|c|c|c|c|c|}
\hline Study and year & Sensitivity \% & Specificity \% & PPV \% & NPV\% & Accuracy \% \\
\hline Levitt et ${ }^{[11]}$ & 90.0 & 100 & 100 & 96.88 & 97 \\
\hline Bajwaet al $^{[48]}(2007)$ & 97.44 & 100 & 100 & 96.88 & $98.5 \%$ \\
\hline Sagelet al $^{[5]} \quad(1977)$ & 100 & 99.05 & 95.65 & 100 & 99 \\
\hline Present study & 96.55 & 96.77 & 96.55 & 96.77 & 96.6 \\
\hline
\end{tabular}

Table 11:- Role of usg in evaluation of renal masses in different studies

\begin{tabular}{|c|c|c|c|c|c|}
\hline Study and year & Sensitivity (\%) & Specificity (0\%) & PPV(\%) & NPV(\%) & Accuracy $(\%)$ \\
\hline${\text { Warshauer et al }{ }^{[25]}(1988)}^{[5]}$ & & 91 & 82 & 73 & \\
\hline $\begin{array}{c}\text { Dachille et al } \\
(2005)\end{array}$ & 80 & 95 & & & \\
\hline $\begin{array}{c}\text { Levitt et al }^{[1]} \\
(1978)\end{array}$ & 60 & 100 & 100 & 84 & 87 \\
\hline $\begin{array}{c}\text { Bajwa et al }^{[48]} \\
(2007)\end{array}$ & 94.87 & 100 & 100 & 93.94 & 85.71 \\
\hline King $^{[1]}(1972)$ & 89.66 & 95.4 & 86.67 & 96.5 & 93.9 \\
\hline Present study & 89.66 & 87.10 & 86.6 & 90.0 & 88.3 \\
\hline
\end{tabular}

Most common appearance of RCC masses was solid 22 (84\%) on USG as against 24 (85\%) on CT .

2 masses were cystic on USG and out of these, 1 was cystic on CT. Two lesions showed combined solid and cystic components on both modalities.

Most common echopattern observed was isoechoic(57.6\%) followed by heterogenouson USG as against $96 \%$ on CT in our study.

These findings are in agreement with the study of Hatimota et al ${ }^{[46]}(2005)$ where most renal cell carcinomas had a solid appearance. On USG, the most common appearance of RCC was predominantly isoechoic to normal renal parenchyma (78\%) followed by hypoechoic and hyperechoic lesions. On CT, most of the lesions of RCC were heterogeneous in attenuation with inhomogeneous contrast enhancement less than that of normal renal parenchyma. 


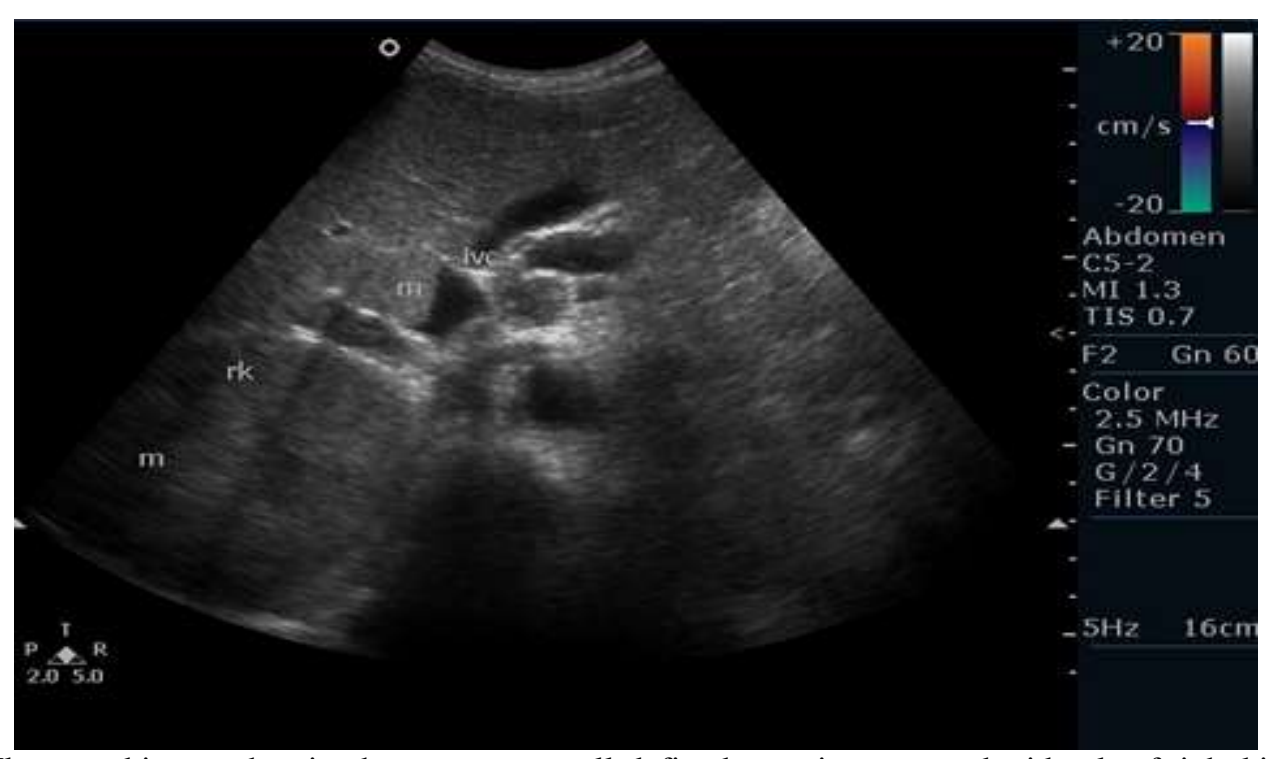

Figure 1:- Ultrasound image showing heterogenous well-defined mass in upper and mid pole of right kidney. IVC is dilated and shows an echogenic material consistent with thrombus.

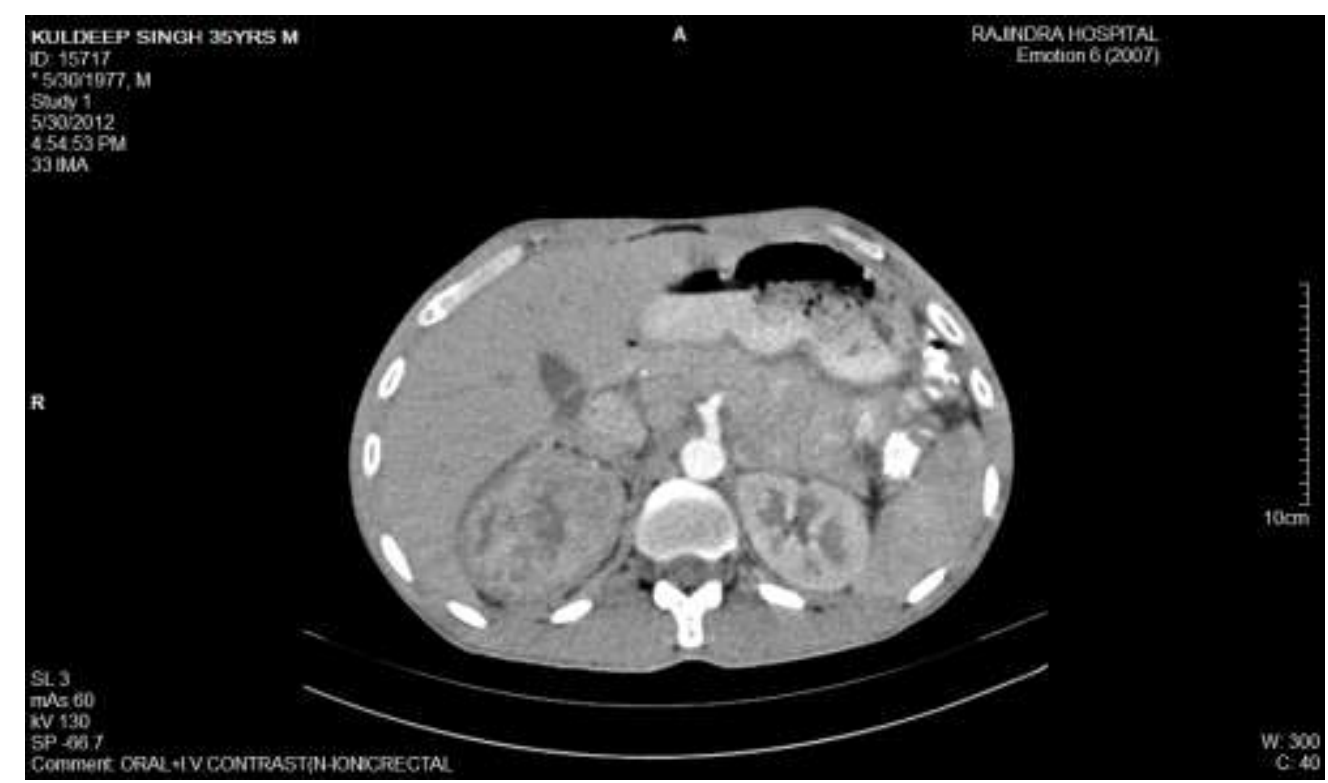

Figure 2:- Computed tomography image shows a heterogeneously enhancing mass is seen in upper and mid pole regions of right kidney. Lumen of IVC is expanded and shows heterogenously enhancing mass suggestive of tumour throm.

CT modality was found to be more sensitive in detection of small lesions as one lesion missed on USG was detected on CT, which was measuring less than $3 \mathrm{~cm}(2.6 \mathrm{~cm})$ in size as shown in Table 9. Similarly, the studies by Kostakopouloset a ${ }^{[29]}(1990)$ and Jamis-Dow et al ${ }^{[39]}(1996)$ showed better sensitivity of CT in detection of small lesions of kidney in comparison to USG but a substantial proportion of small lesions were not visualized with either modality. Study of Bowen et $\mathrm{al}^{[1]}$ also concluded that CT and MRI imaging are nearly ideal techniques for the detection, diagnosis, staging, and preoperative evaluation of small renal masses. So, our study is in consistence with these studies.

Cystic lesions belongs to category III and IV were found to be malignant as shown in Table 5 and it also depicted the usefulness of Bosniak classification in cystic renal lesions.Our study correlates well with study of Curry et 
$\mathrm{al}^{[42]}(2000)$ in which all 18 patients of category IV lesions were malignant. 29 (59\%) of 49 pooled category III masses were malignant.

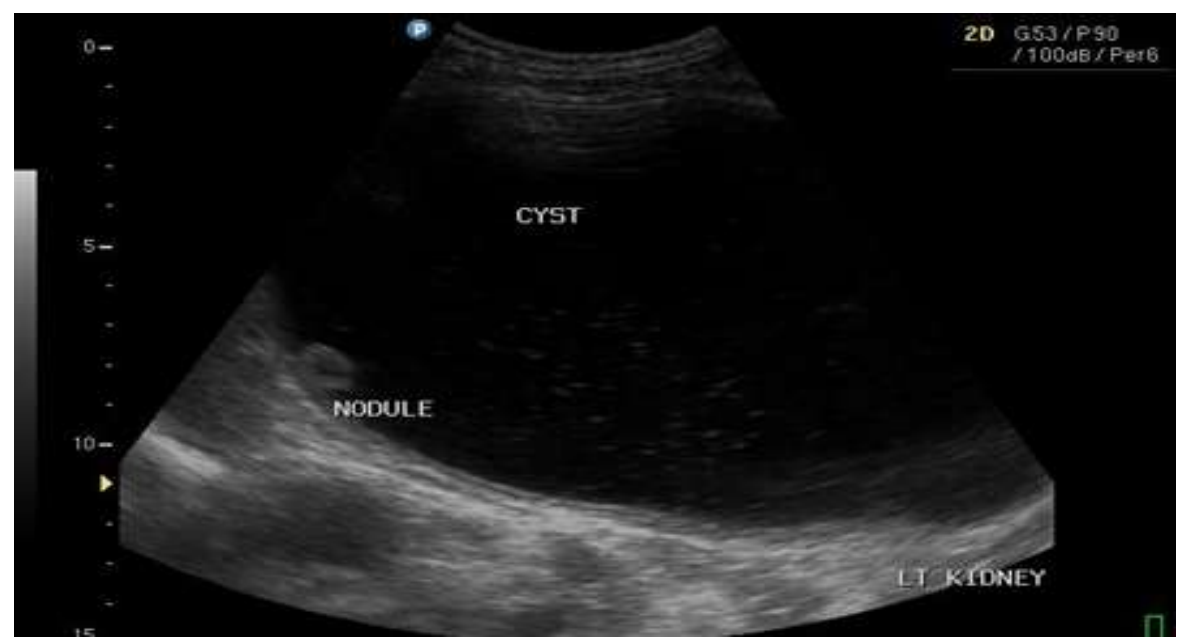

Figure 3:- Ultrasound image shows a well-defined hypoechoiccytic mass with peripheral nodules is seen in left kidney. Internal echoes are also seen in the cystic mass.

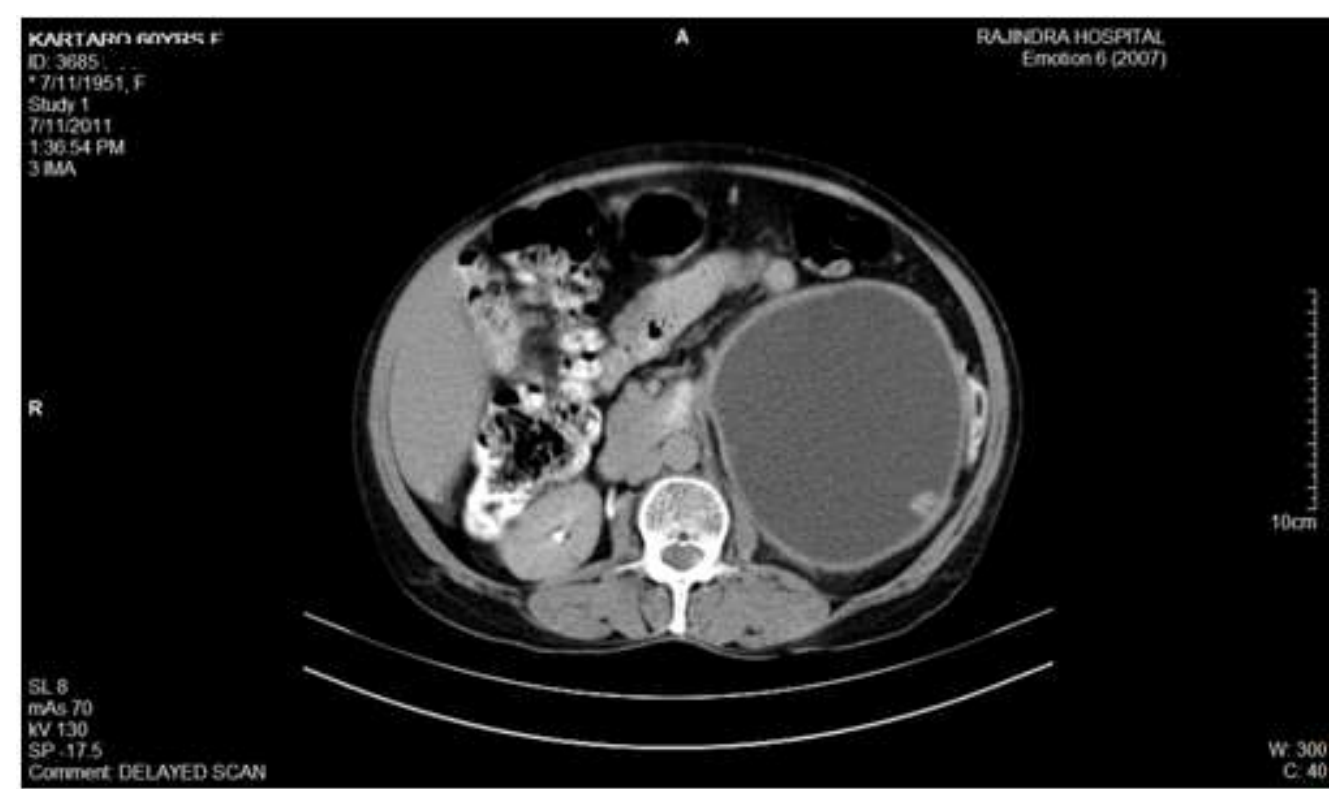

Figure 4:- COMPUTED TOMOGRAPHY - A well-defined thick walled cystic lesion with irregular enhancing nodule is seen arising from upper pole of left kidney.

Calcification and LAP were better seen on CT than USG as shown in Table 6. LAP was seen in 17 cases on CT as against 11 cases on USG. IVC thrombus was found in 2 cases on CT and USG. Our findings are consistent with Weyman et $\mathrm{al}^{[14]}(1982)$ who concluded that $\mathrm{CT}$ has a definite advantage over other radiographic techniques in its ability to evaluate the composition and precisely locating calcifications within renal masses that results in more accurate evaluation of calcified renal masses. 


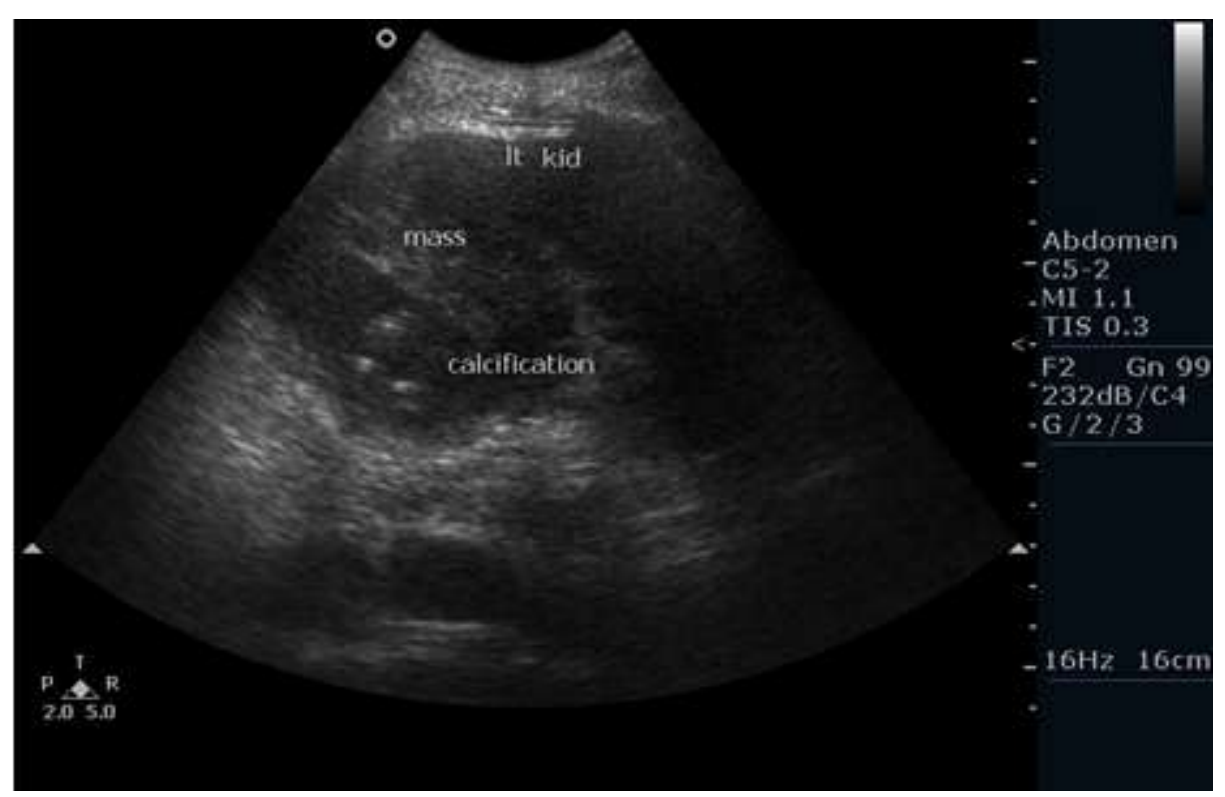

Figure 5:- USG-A heterogenous mass with multiple foci of calcification is seen in upper and mid pole of left kidney.
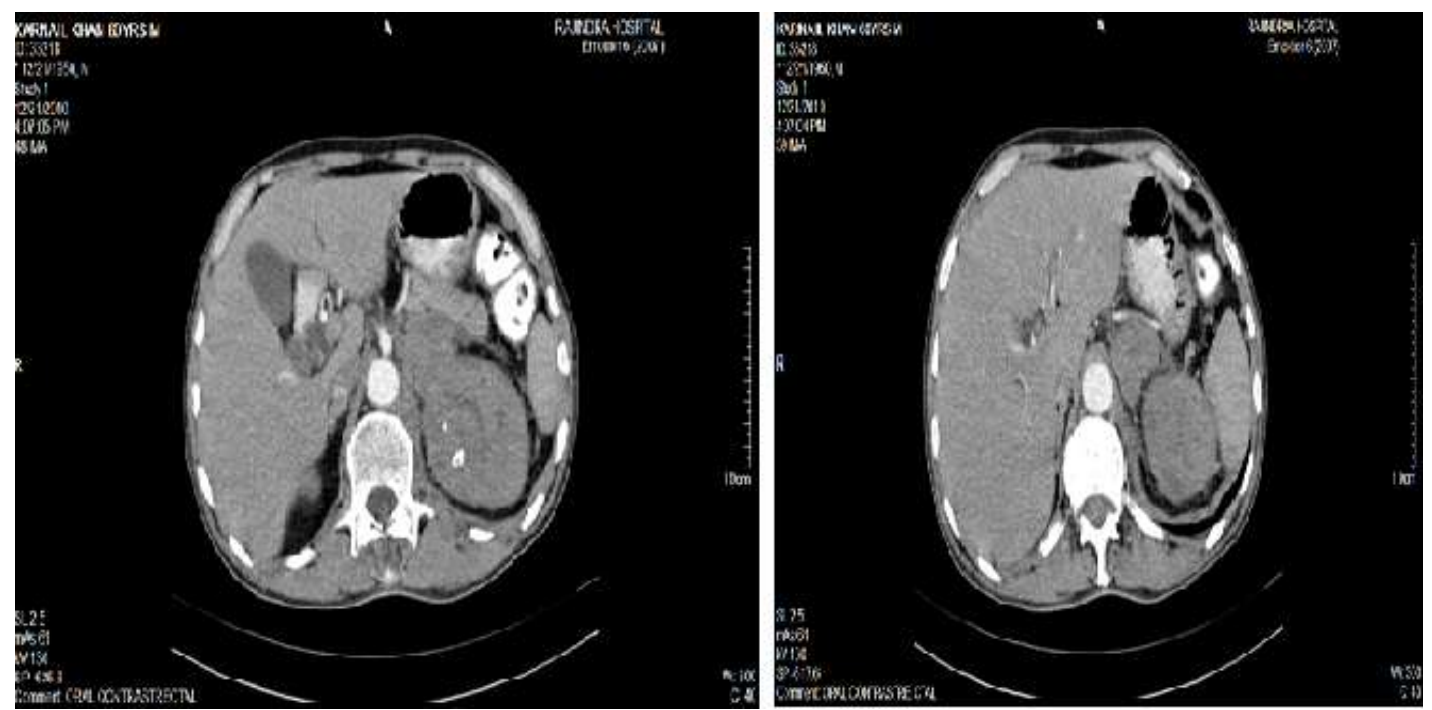

Figure 6:- COMPUTED TOMOGRAPHY - A heterogeneously enhancing mass with calcified foci and necrotic areas is seen involving upper and mid pole of left kidney. Another poorly enhancing mass is seen in left adrenal gland suggestive of adrenal metastasis.

CT additionally detected perinephric extension in 15 cases, collaterals in 6 cases and fat component in one lesion again signifying the high sensitivity and value of CT over USG. Our study correlates well with study of Levine et $\mathrm{al}^{[12]}(1980)$ which concluded that $\mathrm{CT}$ was capable of detecting tumor invasion of perinephric fat and adjacent muscles, which cannot usually be shown by ultrasound. While both CT and ultrasound demonstrate venous and retroperitoneal tumor extension, CT was more reliable.

Our study correlates well with studies of Bajwa et $\mathrm{al}^{[48]}(2007)$ and Zagoria et $\mathrm{al}^{[31]}(1990)$ who concluded that helical $\mathrm{CT}$ is highly sensitive in diagnosing and staging of renal masses.

Our study is in agreement with the study of Hatimota et al ${ }^{[46]}$ (2005) who concluded that USG and CT showed many of the key imaging features used to characterize most of the renal neoplasms. However, some lesions remain indeterminate and require percutaneous biopsy to confirm the diagnosis. 
2 children with Wilm'stumour were less than 5 years old and 1 child was 9 years old as shown in Table 7. Study conducted by Paltiel $^{[2]}$ (2007) concluded that most Wilm's tumors appear within the first 5 years of life. Mean age group was 54 months in our study. Study of Breslow et al ${ }^{[54]}$ (1988) concluded that median ages for Wilm'stumour at diagnosis were 36.5 and 42.5 month.

One child in present study with Wilm stumour was $9 \mathrm{yr}$ old, which doesnot correlate with these studies. Late presentation of child could be the reason.

Echopattern of Wilm'stumour on USG was heterogenous and hyperechoic in one lesion and heterogenous in other two lesions as shown in Table 7. Appearance was heterogenous in all three cases on CT. These findings are consistent with the study of Paltiel ${ }^{[2]}(2007)$ which showed that Wilm's tumor is typically large, sharply marginatedandhyperechoic relative to the normal renal parenchyma on USG.

Our study correlates with study of Fishman et $\mathrm{al}^{[55]}(1983)$ in which appearance of Wilm'stumour was inhomogeneous on the noncontrast studies and slight enhancement was noted after contrast medium injection.

Perinephric extension and lymph node involvement were better seen on CT than USG as shown in Table 13 in our study which correlates well with the study of Reiimen et $\mathrm{al}^{[22]}(1986)$ which concluded that tumor necrosis and a pseudocapsule were detected more often using CT scans than sonograms. CT was also more sensitive in assessing perinephric extension, lymph node involvement, and bilateral tumors.

Present study is in agreement with study of Patel et al ${ }^{[33]}(1991)$ which showed that US and CT were complementary to one another in evaluation of Wilm's tumor.

2 cases of Angiomyolipoma (AML) were detected in our study by both modalities . However, CT additionally detected 2 more cases, which were missed on USG, by detecting fat densities. Appearances on USG and CT were hyperechoic and heterogenous respectively. Our study correlates with study of Hatimota et $\mathrm{al}^{[46]}(2005)$ where they found that AML lesions appeared as heterogenous lesions with internal fat density on NCCT, and showed inhomogenous enhancement on CECT. Our study also correlates with study of Paspulati et $\mathrm{al}^{[3]}(2006)$ in which characteristic sonographic appearance of AML was a well-defined hyperechoic mass and demonstration of intratumoral fat on CT confirmed the diagnosis of an AML.

Our study is in agreement with study of Bajwa et $\mathrm{al}^{[48]}(2007)$ which demonstrated that presence of even a small amount of fat within the renal mass on CT virtually excluded the diagnosis of RCC and is considered diagnostic of AML. Study of Bosniak et $\mathrm{al}^{[23]}(1988)$ also showed that detecting the existence of fat in a renal lesion by CT established the diagnosis of AML and was the only radiologic finding that could differentiate it from RCC.

1 case was diagnosed as hematoma on USG but when CT was done this lesion contains fat and was found to be AML associated with hemorrhage. Our study correlates with study of Sebastia et $\mathrm{al}^{[40]}(1997)$ who concluded that CT is a useful technique for the initial evaluation of SPH permitting diagnosis of hemorrhage and identification of the underlying cause.

Present study is in consistence with study of Antonopoulos et al $^{[56]}(1996)$ in which computed tomography revealed the complications in angiomyolipoma like compression of pelvicalyceal system in 3 cases, intratumoral bleeding in 2 cases, rupture in 4 cases with subcapsular, perirenal, or pararenal hematoma and extensive intrarenal/parapelvic hematoma, cystic degeneration in 1 case.

Out of 60 patients, 1 patient had a well-defined homogenous mass on USG, which showed a central scar indicative of Oncocytoma on CT, which was later confirmed on biopsy. Thus, our study correlates with study of Quinn et $\mathrm{al}^{[20]}(1984)$ which concluded Oncocytomas can be suggested if a stellate scar is identified within an otherwise homogenous tumor on ultrasound (US) and CT. If the mass appears homogeneous without scar, angiography should be performed.

USG detected 4 metastatic renal lesions as against 7 lesions on CT . Lesions that were missed on USG were smaller in size. CT was better in detecting perinephric extension and lymph nodal involvement in renal masses. Our study correlates with the studies of Kostakopoulos et $\mathrm{al}^{[29]}(1990)$ and Jamis-Dow et $\mathrm{al}^{[39]}(1996)$ which showed better 
sensitivity of CT in detection of small lesions of kidney but this sensitivity is directly proportional to the size of lesion.

Out of 60 patients, 2 were diagnosed as renal lymphoma. Multiple b/l renal hypodense masses associated with retroperitoneal lymphadenopathy were found in 1 patient on USG and CT. 1 renal lesion shows exophytic component on CT. Some of nodal masses cause impression on kidneys and there was encasement of renal vessels by lymph nodes as seen on CT. Bilateral renal masses were seen in second patient on both modalities and these masses were seen displacing the pelvicalyceal system medially. Associated insignificant lymphadenopathy in mesentery and retroperitonium were also found on CT.

Thus, our study is in agreement with study of Chepuri et al ${ }^{[44]}(2003)$ which concluded that multiple bilateral masses were the most common CT appearance in renal lymphoma. Less common presentations were focal solitary masses or an engulfing mass. Retroperitoneal lymph node enlargement and other organ involvements were common associated findings. Our study also correlates with study of Weinberger et $\mathrm{al}^{30}$ which showed that both CT and USG depicted extrinsic effects on the kidneys (either displacement or hydronephrosis) due to adjacent retroperitoneal or mesenteric mass. They concluded that contrast-enhanced CT was superior to sonography for detection of renal lymphoma.

Out of 7 cases of renal abscesses, USG detected 7 lesions, which were later, confirmed on CT scans. USG detected only one lesion in 1 patient while CT found two lesions in that patient. Small size could be the reason for its nondetection on USG. So, our study correlates with the studies of Kostakopoulos et al ${ }^{[29]}$ (1990) and Jamis-Dow et $\mathrm{al}^{[39]}(1996)$ which showed the better sensitivity of CT in detection of small lesions of kidney but this sensitivity is directly proportional to the size of lesion.

CT depicted rim enhancement in 6 lesions, heterogenous enhancement in 2 lesions, perinephric fluid in 1 case, perinephric extension in 6, LAP in 5, psoas abscess in 2, psoas thickening in 2 and intralesional air in 1 case while USG detected perinephric extension in 2, LAP in 3 and psoas thickening in 2 cases shown in Table 16. Psoas abscess was not separately identified on USG from renal abscess.

Our study therefore, correlates with the study of Hoddick et al ${ }^{[17]}$ which showed that computed tomography seems to be the more sensitive method in evaluating severe renal and perirenal infections. Our study is also consistent with study of Soulen et $\mathrm{al}^{[28]}(1989)$ which concluded that USG was not an adequate screening test for detecting lesions that may require invasive therapy. CT was more sensitive for the detection of acute renal inflammatory disease and for defining the extent of disease for planning of radiologic or surgical intervention.

Out of 4 cases of pyelonephritis, 3 were detected on both modalities in our study as shown in Table 10. Appearance was heterogenous in all lesions on both USG and CT. Perinephric extension was seen in 2 cases and perinephric fat stranding in 1 case on CT. CT shows mild thickening of psoas muscle in 1 case and LAP was seen in 1 and 2 cases on USG and CT respectively.Our study correlates with the study of Hoddick et $\mathrm{al}^{[17]}(1983)$ in which they found that computed tomography seems to be the more sensitive method of evaluating severe renal and perirenal infections. 


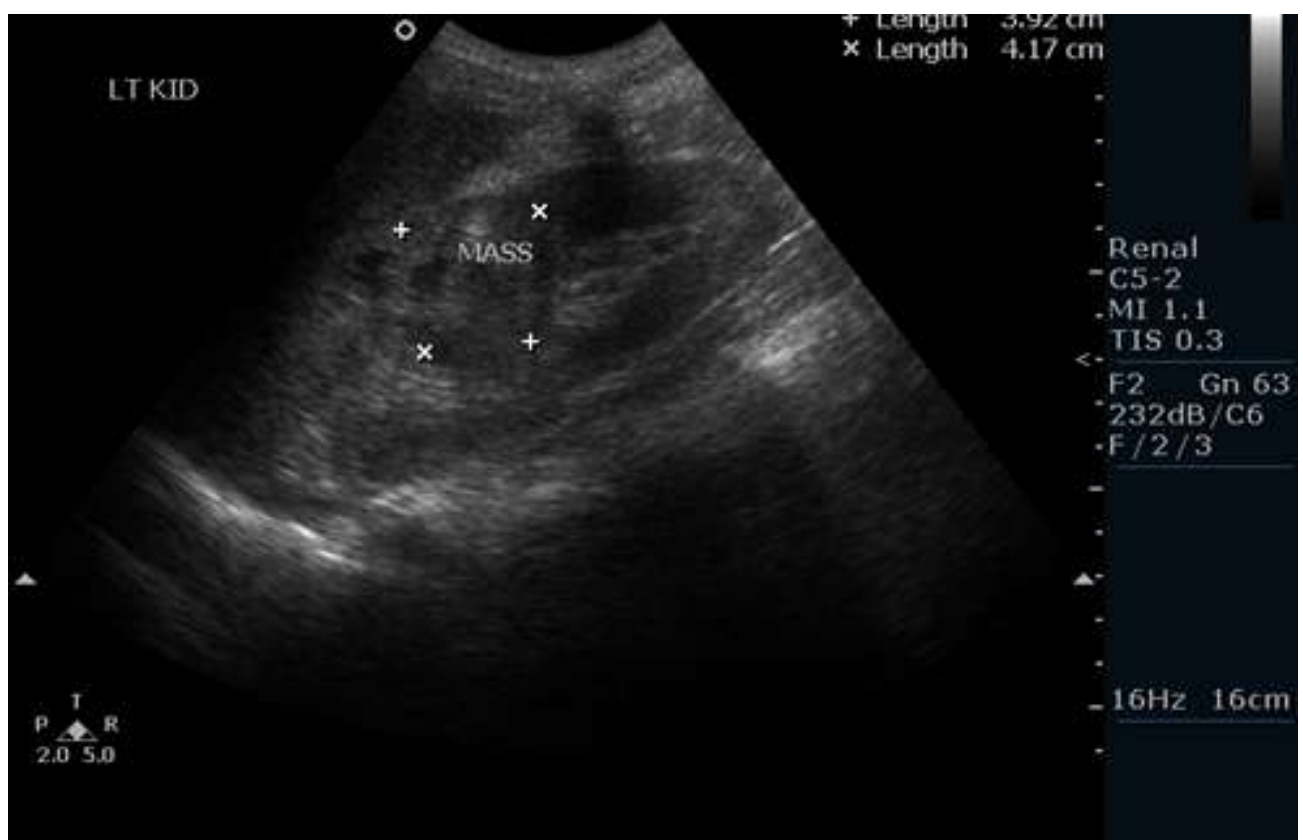

Figure 7:- USG- A poorly defined heterogenouslesion is seen in upper and mid pole of left kidney.

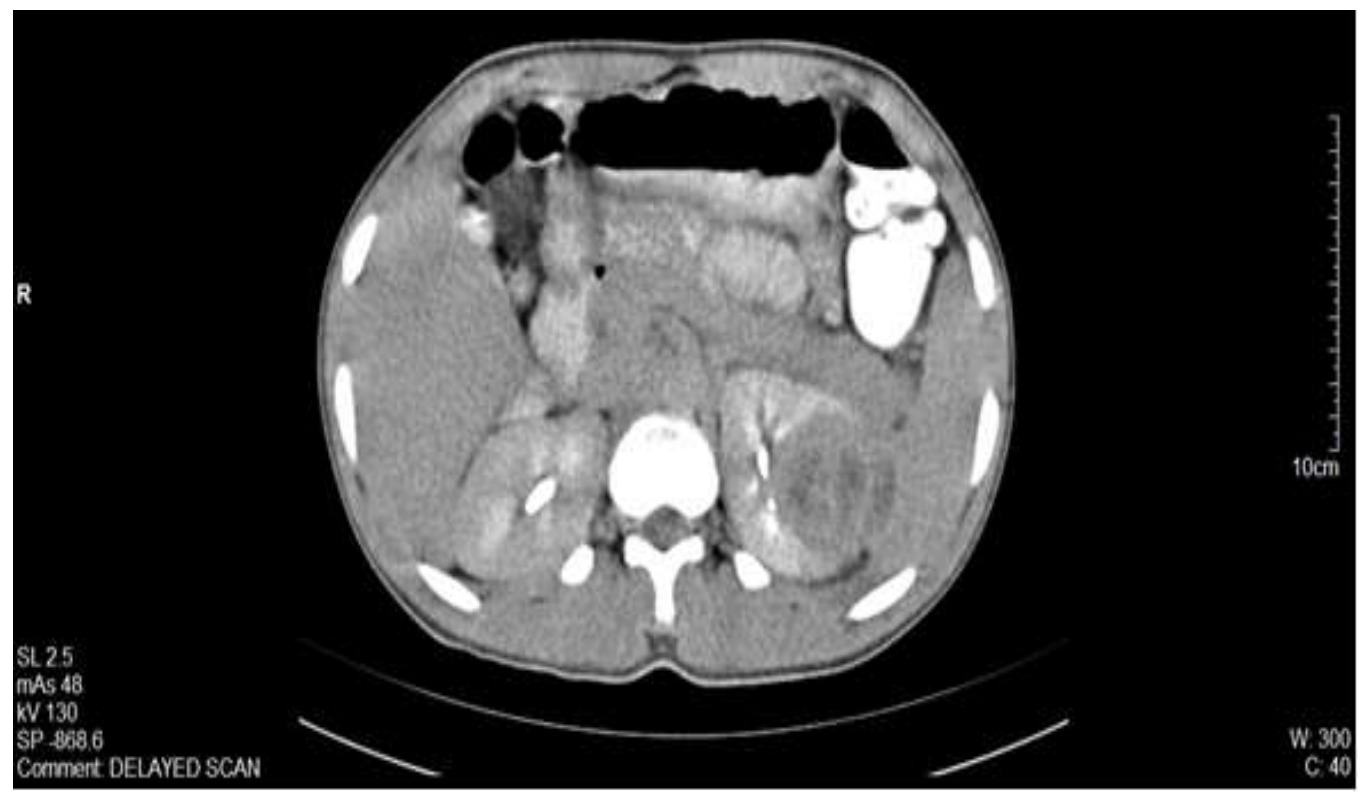

Figure 8:- COMPUTED TOMOGRAPHY - A heterogeneously enhancing mass with poorly defined margins is seen in upper and mid pole of left kidney. Mild perinephric stranding is seen.

USG and CT showed a heterogenous mass with calculus in 1 patient as shown in Table 11. Perinephric extension and fatty component was also seen on CT and it was diagnosed as a case of xanthogranulomatous pyelonephritis, which was later on confirmed pathologically. Our study correlates with study of Goldman et al ${ }^{[18]}(1984)$ which concluded that CT played a role in diagnosis and preoperative planning to demonstrate the extent of extrarenal disease that is poorly depicted by other means.

\section{Conclusion:-}

Ultrasonography is often the initial modality for imaging of the kidneys, although contrast enhanced CT is an established imaging modality for the diagnosis of renal tumors. Ultrasonography is easily performed without the need for sedation or ionizing radiation and without requirement of intravenous contrast injection so it is valuable for 
children, pregnant women and those having impaired renal function or sensitivity to iodinated contrast.It is portable and relatively inexpensive. CT has a profound impact on diagnostic uroradiology among all modern modalities. It has proven useful for imaging the complete spectrum of renal and ureteral disorders. It allows studies in patients who have dense renal calcification or in whom USG is technically difficult. Helical CT is highly sensitive in diagnosing and staging of renal masses. CT is capable of detecting tumor invasion of perinephric fat and adjacent muscles, which cannot usually seen by ultrasound. While both CT and ultrasound demonstrate venous and retroperitoneal tumor extension, CT is more reliable.

\section{Bibliography:-}

1. Bowen DR and Case JT. Imaging of Small Renal Masses: A Medical Success Story. AJR 2000;175:945-55.

2. Paltiel HJ.Sonography of Pediatric Renal Tumors. Ultrasound Clin 2007;2:89-104.

3. Paspulati RM and Bhatt S.Sonography in Benign and Malignant Renal Masses. Ultrasound Clin 2006;1:25-41.

4. Weber TM.Sonography of benign renal cystic disease. Ultrasound Clin 2006;1:15-24.

5. Sagel SS, Stanley RJ, Levit RG,Geisse G.Computed Tomography of the Kidney. Radiology 1977;124:359-70.

6. Bechtold RE, Dyer RB, Zagoria RJ, Chen MYM.The Perirenal Space:Relationship of Pathologic Processes to Normal Retroperitoneal Anatomy.RadioGraphics 1996;16:841-54.

7. Daly KP, P.Ho C, Persson DL, Gay SB. Traumatic Retroperitoneal Injuries: Review of Multidetector CT Findings.RadioGraphics 2008;28:1571-90.

8. Tirkes T, Sandrasegaran K, Patel AA, Hollar MA, Tejada JG, Tann M et al. Peritonealand Retroperitoneal Anatomy and Its Relevance for Cross-Sectional Imaging.RadioGraphics 2012;32:437-51.

9. King DL. Renal ultrasonography an aid in clinical evaluation of renal masses. Radiology 1972;105:633-40.

10. Schaner EG, Balow JE, Doppman JL.Computed Tomography in the Diagnosis ofsubcapsular and perirenal hematoma.Am J Roentgenol 1977;129:83-8.

11. Levitt RG, Gelsse GG, Sagel SS, Stanley RJ, Evens RG, Koehler RE et al. Complementary Use of Ultrasound and Computed Tomography in Studies of the pancreas and Kidney. Radiology 1978;126:149-52.

12. Levine E, Maklad NF, Rosenthel SJ, lee KR, Weigel J.Comparisonof computed tomography and ultrasound in abdominal staging of renal cancer. Urology. 1980;16(3):317-22.

13. Hartman DS, Davis CJ, Goldman SM, Friedman AC, Fritzsche P. Renal Lymphoma:Radiological Pathologic Correlation of 21 Cases. Radiology1982;144:759-66.

14. Weyman PJ, McClennan BL, Lee JKT, Stanley RJ. CT of Calcified Renal Masses. AJR 1982;138:1095-9.

15. Levine E andHuntrakoon M. Computed Tomography of Renal Oncocytoma. AJR 1983;141:741-6.

16. Heiken JP, Gold RP, Schnur MJ, King DL, Bashist B, Glazer HS. Computed tomography of renal lymphoma with ultrasound correlation. J Comput Assist Tomogr. 1983;7(2):245-50.

17. Hoddick W, Jeffrey RB, Goldberg HI, Federle MP, Laing FC. CT and Sonography of Severe Renal and Perirenal Infections. AJR 1983;140:517-20.

18. Goldman SM, Hartman DS, Fishman EK, Finizio JP, Gatewood OM, Siegelman SS. CT of xanthogranulomatous pyelonephritis: radiologic-pathologic correlation. AJR Am J Roentgenol. 1984;142(5):963-9.

19. Press GA, McClennan BL,Melson GL,Weyman PJ, Mauro MA, Lee JKT.Papillary Renal Cell Carcinoma: CT and Sonographic Evaluation. AJR1984;143:1005-9.

20. Quinn MJ, Hartman DS, Friedman AC, Sherman JL, Lautin EM, Pyatt RS et al.Renal oncocytoma: new observations. Radiology. 1984;153(1):49-53.

21. Fitch S, Parvey LS, Wilimas J, Buckley PJ, Webber BL. Developmental cystic renal neoplasms in children. Diagnostic imaging characteristics. ComputRadiol. 1985; 9(3):149-58.

22. Reimen TA, Siegel MJ, Shackelford GD. Wilms tumor in children: abdominal CT and US evaluation. Radiology. 1986;160(2):501-5.

23. Bosniak MA,Megibow AJ, Hulnick DH, Horii S, Raghavendra BN. CT Diagnosis of Renal Angiomyolipoma: The Importance of Detecting Small Amounts of Fat. AJR 1988;151:497-501.

24. Hartman DS, Davidson AJ, Davis CJ, Goldman SM. Infiltrative Renal Lesions: CT-Sonographic- Pathologic Correlation. AJR 1988;150:1061-4.

25. Warshauer DM, McCarthy SM, Street L, Bookbinder MJ, Glickman MG, Richter J et al. Detection of Renal Masses: Sensitivities and Specificities of Excretory Urography/ Linear Tomography, US, and CT.Radiology 1988;169:363-5.

26. Zeman RK, Cronan JJ, Rosenfield AT, Lynch JH, Jaffe MH, Clark LR.Renal cell carcinoma: dynamic thinsection CT assessment of vascular invasion and tumor vascularity. Radiology. 1988;167(2): 393-6. 
27. Belville JS, Morgentaler A, Loughlin KR, Tumeh SS. Spontaneous Perinephric and Subcapsular Renal Hemorrhage: Evaluation with CT, US, and Angiography.Radiology 1989;172:733-8.

28. Soulen MC, Fishman EK, Goldman SM, Gatewood OM. Bacterial renal infection: role of CT. Radiology. 1989;171(3):703-7.

29. Kostakopoulos A, Antonopoulos P, Drosos C, Stavropoulos N, Picramenos D, Deliveliotis C. Small lesions of the kidney: CT evaluation comparison with ultrasound.ActaUrol Belg. 1990;58(3):73-85.

30. Weinberger E, Rosenbaum DM, Pendergrass TW. Renal Involvement in Children with Lymphoma: Comparison of CT with Sonography. AJR 1990;155:347-9.

31. Zagoria RJ, Wolfman NT, Karsteadt N, Hinn GC, Dyer RB, Chen YM. CT features of renal cell carcinoma with emphasis on relation to tumor size. Invest Radiol1990;25(3):261-6.

32. Paivansalo M, Lahde S, Hyvarinen S, Kallioinen M, Jalovaara P. Renal angiomyolipoma. Ultrasonographic, CT, angiographic, and histologic correlation. ActaRadiol 1991;32(3):239-43.

33. Patel K, Mahboubi S, Sherman NH, Rosenberg HK. Diagnosis and follow-up of children with Wilms' tumor: correlative study of ultrasound and computed tomography. Report of eighteen cases.Ann Radiol(paris). 1991;34(6-7):376-82.

34. Fultz PJ, Hampton WR, Totterman SM. Computed tomography of pyonephrosis. Abdom Imaging. 1993;18(1):82-7.

35. Masuda F, yamazaki H, Imanaka K, Kobari T, Haseqawa N, Kishi D. Computed tomography in the diagnosis of transitional cell carcinoma of the renal pelvis. Nihon HinyokikaGakkaiZasshi. 1993;84(10): 1835-8.

36. Yamashita Y,Ueno S, Makita O,Ogata I ,Hatanaka Y,Watanabe O et al. Hyperechoic Renal Tumors: Anechoic Rim and Intratumoral Cysts in US Differentiation of Renal Cell Carcinoma from Angiomyolipoma. Radiology 1993;188:179-82.

37. Cohan RH, Sherman LS, Korobkin M, Bass JC, Francis IR.Renal Masses: Assessment of CorticomedullaryPhase andNephrographic-Phase CT Scans. Radiology 1995;196:445-51.

38. Einstein DM,Herts BR, Weaver R,Obuchowski N,ZeppR , Singer A.Evaluation of Renal Masses Detected by Excretory Urography: Cost-Effectiveness of Sonography Versus CT. AJR 1995;164:371-5.

39. Jamis-Dow CA,Choyke PL, Jennings SB,LinehanWM ,Thakore KN, Walther MM. SmallRenal Masses: Detection with CT versus US and Pathologic Correlation. Radiology 1996;198:785-8.

40. Sebastia MC, Perez Mollina MO, Alverez castells A, Quiroga S, Pallisa E. CT evaluation of underlying cause in spontaneous subcapsular and perirenal hemorrhage. EurRadiol1997;7(5):686-90.

41. Macari M, Bosniak MA. Delayed CT scan to evaluate renal masses incidentally discovered at contrast enhanced CT: demonstration of vascularity with deenhancement. Radiology 1999;213:674-80.

42. Curry NS, Cochran ST, Bissada NK. Cystic Renal Masses: AccurateBosniak Classification Requires AdequateRenal CT. AJR 2000;175:339-42.

43. Israel GM, Bosnaik MA, Slywotzky CM, Rosen RJ. CT differentiation of large exophytic renal angiomyolipomas and perirenalliposarcomas.AJR AM J Roentgenol2002;179(3):769-73.

44. Chepuri NB, Strouse PJ, Yanik GA. CT of Renal Lymphoma in Children.AJR 2003;180:429-31.

45. Toprak U,Erdoğan A, Gülbay M,Karademir MA,Paşaoğlu E, Akar OE. Preoperative evaluation of renal anatomy and renal masses with helical CT, 3D-CT and 3D-CT angiography. DiagnIntervRadiol 2005;11:35-40.

46. Hatimota P, Vashist S, Aggarwal K, Kapoor A, Gupta NP. Spectrum of US and CT findings in renal neoplasms with pathological correlation. Ind J RadiolImag 2005;15:1:117-25.

47. Hasni BI, Jemni H, Arifa N, Chebil M, Ben SN, Tlili K. Imaging of renal hydatid cyst based on a series of 41 cases.Prog Urol. 2006;16(2):139-44.

48. Bajwa RPS, Sandhu P, Aulakh BS, Sandhu JS, Saggar K, Ahluwalia A.Helical CT Evaluation of Renal Mass Lesions: A Prospective Study. Jiacm 2007;8(3):262-4.

49. Zhang J, Lefkowitz RA, Ishill NM, Wang L, Moskowitz CS, Russo P et al. Solid Renal Cortical Tumors: Differentiation with CT. Radiology 2007;244:494-504.

50. Lindblad P. Epidemiology of renal cell carcinoma. Scand J Surg. 2004;93:88-96.

51. Lipworth L, Tarone RE, McLaughlin JK. The epidemiology of renal cell carcinoma. J Urol 2006;176:2353-8.

52. Ng CS, Wood CG, Silverman PM, Nizar M, Tannir NM, Tamboli P, Sandler CM.Renal Cell Carcinoma: Diagnosis,Staging, and Surveillance. AJR 2008; 191:1220-1232

53. Dachille G, Erinnio M, Cardo G, Maselli FP, Vestita G, Ludovico GM et al.Detection rate of ultrasound vs CT scan in clinical staging accuracy of renal tumors pT1NxMx. Arch ItalUrolAndrol. 2005;77(3):149-50.

54. Breslow N, Beckwith JB, Ciol M, Sharples K. Age Distribution of Wilms' Tumor: Report from the National Wilms' Tumor Study. Cancer Res 1988;48:1653-7. 
55. Fishman EK, Hartman DS, Goldman SM, Siegelman SS.The CT appearance of Wilms tumor.J Comput Assist Tomogr 1983;7(4):659-65.

56. Antonopoulos P, Drossos C, Triantopoulou C, Picramenos D, Dalamarinis C, Costacopoulos A. Complications of renal angiomyolipomas: CT evaluation.Abdom imaging 1996;21(4):357-60.

57. Emedicine.medscape.com/380543 renal cell carcinoma. 